\title{
LÓGICAS DE AÇÃO DE ESCOLAS PRIVADAS EM REDE NA VOZ DE SEUS GESTORES
}

\author{
Isabel Lelis ${ }^{1}$, Silvana Mesquita ${ }^{2}$
}

\begin{abstract}
Resumo:
Este artigo apresenta os resultados de uma pesquisa sobre "escolas privadas em rede", que vêm se expandindo como alternativa para as famílias de uma "nova classe média”. A proposta é analisar as percepções de gestores sobre o ensino e o trabalho docente, a partir de duas escolas investigadas. Os dados partem de entrevistas com a equipe de gestão e dialogam com uma literatura educacional sobre as lógicas de ação presentes nesse novo tipo de instituição que ganha espaço no mercado escolar, caracterizado pela centralização do ensino e pelo uso de sistemas apostilados. São apresentados a cultura institucional da rede pesquisada e o processo de construção de uma identidade, associados aos dispositivos estruturantes da proposta pedagógica e os impactos sobre o trabalho docente. Constata-se a hegemonia de empresas educacionais controlando o campo mercadológico e ideológico no sistema de ensino investigado, com forte regulação sobre a prática pedagógica dos professores.
\end{abstract}

Palavras-chave: Escolas Privadas de Rede. Gestão Escolar. Trabalho Docente. Sistemas Apostilados.

\footnotetext{
1 Professora do Departamento de Educação da PUC- Rio, doutora em Educação, coordena o grupo de pesquisa GEPPE de estudos sobre o professor e o ensino.

E-mail: isabell@puc-rio.br

2 Professora do Departamento de Educação da PUC-Rio, doutora em Educação, coordena o grupo de pesquisa PROFEX de estudos sobre a Profissão, Formação e Exercício docente.

E-mail: silvanamesquita@puc-rio.br
} 


\title{
LOGICS OF ACTION OF A PRIVATE SCHOOL CHAINS ACCORDING TO ITS MANAGERS
}

\author{
Isabel Lelis, Silvana Mesquita
}

\begin{abstract}
:
The text presents the results of a research on "private school chains", which have been expanding as an alternative to the families of a "new middle class". The proposal is to analyze managers' perceptions on teaching and teacher's work, from two schools studied. The data come from interviews with the management team and are linked to educational literature on the logic of action present in this new type of institution that gains space in the educational market, characterized by the centralization of education and the use of textbook systems. We present the institutional culture of the researched chains and the process of constructing an identity, associated to the structuring devices of the pedagogical plan and the impacts on the teachers' work. It is observed the hegemony of educational companies which control the market and ideological field in the educational system we investigated, which also shows strong oversight over the pedagogical practices of teachers.
\end{abstract}

Keywords: Private Schools Chains. School Management. Teaching Work. Textbook Systems 


\section{Introdução}

Assistimos, nas últimas décadas, ao aparecimento de grandes empresas educacionais voltadas para o ensino superior e a educação básica. Originárias de cursinhos prévestibulares bem-sucedidos, que conseguiram aprovar parte de seus alunos em cursos superiores, essas instituições ampliaram-se por vários estados do Brasil, por meio de franquias para redes privadas (ADRIÃO; GARCIA; BORGUI; ARELARO, 2009).

Uma matéria publicada no Jornal O Globo (24/04/2013) já alertava para a fusão dos dois maiores grupos de educação (Kroton Educacional e Anhanguera Educacional) em um só e para o interesse desse grupo em investir na escolarização da "nova classe média” brasileira, em especial nas regiões Norte e Nordeste do Brasil. Com mensalidades em torno de $\mathrm{R} \$ 500,00$ no curso presencial e de $\mathrm{R} \$ 250,00$ no ensino à distância, a nova empresa quer buscar alunos das classes $\mathrm{C} \mathrm{e} \mathrm{D,} \mathrm{sendo} \mathrm{que,} \mathrm{no} \mathrm{ensino}$ superior, o horizonte é o de ampliar o percentual de estudantes que tentam estudos custeados pelo FIES, programa de financiamento estudantil do governo federal.

Paralelamente a esse novo tipo de empreendimento educacional, vimos o aparecimento, em algumas capitais brasileiras, das chamadas "escolas privadas em rede” na Educação Básica. No caso da cidade do Rio de Janeiro, conforme entrevista, em 2011, com Wanderley Quedo, então presidente do SINPRO-Rio, essas escolas atendem as classes C, D e E, apresentam uma infraestrutura física razoável, garantem salários aos professores dentro dos patamares desse sindicato.

Este artigo traz, especificamente, parte dos resultados de uma pesquisa institucional realizada entre os anos de 2012 e 2016, intitulada "O trabalho docente em escolas privadas de setores populares: um objeto esquecido”. O ponto de partida foi a necessidade de investigar a realidade de professores imersos em um tipo de escola muito diferente daquelas da rede municipal do Rio de Janeiro e mesmo das escolas particulares, leigas ou confessionais, frequentadas pelas elites cariocas. Há um silêncio sobre escolas particulares que atendem os segmentos das classes C e D e os professores que integram o corpo docente.

A rede investigada caracteriza-se por ser uma das maiores e mais antiga do Rio de Janeiro. Fundada desde 1967, foi crescendo e multiplicando o número de escolas na busca por atrair famílias de menor poder aquisitivo. São quinze as escolas que compõem a instituição, da Educação Infantil ao Ensino Médio, com um quadro de 900 professores, atendendo, no ano de 2013, a um total de cerca de 14.000 alunos em bairros da zona norte e oeste da cidade do Rio de Janeiro. Essas escolas pertencem a um único proprietário, considerado liderança educacional no mercado escolar do subúrbio carioca. Dada à impossibilidade de realizar a investigação nas quinze instituições, em termos do trabalho de campo, optamos por selecionar dois estabelecimentos de ensino, um na zona norte e o outro na zona oeste.

Para efeito deste artigo, a proposta é a de analisar, especificamente, as percepções 
dos gestores sobre as lógicas de funcionamento da instituição, a cultura institucional e as formas de regulação adotadas sobre o trabalho dos professores, eixos estruturantes da identidade da instituição. Por se tratar de fenômeno que tem se desenvolvido, principalmente, nos grandes centros urbanos, as escolas privadas em rede vêm se expandindo como uma alternativa para as famílias de uma nova classe média.

A chamada "nova classe média" estrutura-se pela ascensão econômica de extratos mais baixos das camadas médias e de setores populares. São famílias que estudaram em escolas públicas, algumas cursaram universidades privadas, em sua maioria, são trabalhadores ou pequenos empresários, com jornadas de trabalho longas e pouco tempo para lazer. Objetivam melhores condições de vida, privilegiando a aquisição de bens de consumo, mas o capital econômico e cultural é restrito e limitado (SOUZA, 2011).

Foram oito as entrevistas realizadas: com o proprietário e fundador da rede; com a supervisora pedagógica geral; além de dois diretores das duas unidades investigadas e das respectivas coordenadoras pedagógicas de cada segmento do ensino fundamental. As entrevistas foram realizadas nas próprias unidades escolares, o que permitiu incorporar, na investigação, as observações dos diários de campo feitas durante as visitas às escolas.

\section{A cultura institucional}

Na percepção dos gestores, a rede Ribeirão (nome fictício) de ensino tem uma história de reconhecimento entre os setores populares e a camada média baixa. A sua ampliação nesses 40 anos de existência é vista com orgulho pelos entrevistados, na medida em que foram muitos sacrifícios e lutas travadas para que ela ocupasse um lugar de destaque no mercado escolar. No depoimento de seu fundador e proprietário, a rede começa em uma pequena "casinha velha”, nos anos 60, atendendo 19 alunos.

Sua expansão foi explicada por um conjunto de fatores, como a crise do sistema público de ensino e o crescimento das zonas oeste e norte, com a construção de grandes condomínios residenciais. Entre os anos 60 e os anos 90, várias escolas vão sendo compradas ou construídas, sendo o ano de 1999 um marco, quando se consolida a Rede Ribeirão de ensino, voltada para atender a um público escolar heterogêneo do ponto de vista dos níveis socioeconômico e cultural.

Com o intuito de driblar uma fase difícil, provocada por políticas de universalização do ensino fundamental, o grupo buscou, inicialmente, convênios com outras empresas, no sentido de estabelecer parcerias e garantir a oferta de um padrão de ensino às famílias de menor poder aquisitivo que não tinham condições de pagar por determinadas faixas de mensalidade.

Mais tarde, outros mecanismos foram acionados, como a compra de sistemas apostilados de ensino, a oferta de bolsas de estudo e um forte investimento em marketing junto aos pais dos alunos. Todas essas características evidenciam um 
perfil de certa forma camaleão como marca da gestão do grupo, pois as estratégias acionadas, intencionalmente, pelo diretor da escola são orientadas por um constante processo de adaptação às mudanças sociais e às necessidades do público que atende.

Para Oliveira (2007), o processo de desenvolvimento de um setor empresarial na educação não é recente e remonta ao período do governo militar. O que há de novo, na educação básica, abrange a venda de materiais pedagógicos e pacotes educacionais que incluem aluguel de marca, os mecanismos de franquias, a avaliação e formação em serviço dos professores. O aparecimento desse tipo de instituição, para esse autor, foi à resposta ao aumento da demanda, resultante da regularização do fluxo no ensino fundamental e consequente crescimento do ensino médio.

Com o objetivo de administrar a rede do ponto de vista dos recursos humanos e financeiros, o proprietário construiu um prédio ao lado da primeira escola da rede e, ali, instalou um departamento que centraliza a contabilidade, os recursos humanos, o setor jurídico e de cobrança. Toda essa estrutura administrativa tem, entre outras funções, o objetivo de administrar o problema da falta de pagamento e unificar o trabalho da rede. Nas suas palavras:

\footnotetext{
Nós temos um departamento comercial, ou seja, todas as cantinas, malharia pertencem ao grupo, não a escola porque a escola não pode ser comércio. Então, nós criamos várias empresas pequenas com a participação do meu filho e meus sobrinhos. Eu tenho vários parentes trabalhando na minha empresa (Proprietário da rede investigada).
}

Parece que estamos diante de um fenômeno em que se afirma um habitus empresarial transposto para a escola no sentido de facilitar a vida das famílias. Esse habitus implica a venda do material escolar, material pedagógico, uniforme, mochilas, sob a forma de parcelamento com cartão de crédito. A expressão pedagogia da habituação foi criada com o sentido de traduzir o conjunto de dispositivos que visa a produção de nova subjetividade para os estudantes. Esse conceito traduz-se também pela reafirmação e consolidação de práticas que objetivam a regulação comportamental e cultural, de forma a habituá-los à lógica hegemônica do capital nesse novo período de acumulação. Novas conexões são estabelecidas entre a escola e a dinâmica empresarial, provocando um ajustamento da escola ao universo mercantil, segundo os desígnios do capital (SILVA e SOUZA, 2009).

O processo de expansão da escola também contou com uma visão comercial de seu proprietário, ao optar por adquirir escolas menores que não resistiram aos tempos de crise. Na visão dos gestores, a rede procurou também reinvestir os lucros em novas ações, visando a modernização dos equipamentos e a ampliação dos espaços, além de investimentos em estratégias de divulgação e marketing.

A escola ainda desenvolve um programa em relação ao seu público com o atendimento a atletas. São alunos bolsistas que formam os "times" da escola para participar dos 
torneios estudantis. Mais uma estratégia adotada como marketing da gestão, pois os bons resultados nos torneios esportivos contribuem para colocar o nome da rede em evidência, favorecendo a associação entre uma boa escola e o êxito nos resultados esportivos.

Essa característica de camaleão, buscando adaptar-se aos diversos contextos sociais pode ser percebida, também, em relação às variações econômicas da "nova classe média” que a escola atende. Segundo os entrevistados, o público familiar que chega até a escola é bastante heterogêneo, principalmente, em relação às diferentes áreas geográficas em que se localizam as escolas da rede. Assim, outra estratégia da rede refere-se às variações nos valores das mensalidades escolares, pois a direção, no intuito de ampliar \manter sua clientela, recorre a uma política de concessão de bolsas de estudo e reduções nos valores das mensalidades a serem pagos. Para o diretor da unidade:

Nós temos de bolsa integral hoje nós temos uma média de 20\% (vinte por cento) dos nossos alunos tem bolsas integrais, E tem, além do preço de tabela, tem mais $10 \%$ (dez por cento), tem mais $15 \%$ (quinze por cento), tem mais $20 \%$ (vinte por cento) de desconto, porque todas as famílias que nos procuram com dificuldades nosso interesse é atender, é lógico, evidente que a gente não tem como atender a todos, mas o nosso interesse é atender.

Para os gestores, em que pesem as diferenças existentes, há um sentimento de que as classes menos privilegiadas atendidas por essa rede de ensino buscam, na escola privada, a consolidação de um status de ter o filho na rede particular de ensino. Além disso, os gestores reconhecem que são as famílias de extratos mais desfavorecidos as que menos investem em práticas culturais, deixando a cargo da escola as idas ao teatro, aos museus, às exposições de arte, pois parecem ter a percepção de que a escola que cobra mensalidades deve ampliar a cultura dos seus filhos com aquela dita mais erudita. Para a coordenadora da escola A:

É um investimento que eles fazem, mas eu vejo a classe C assim, da seguinte forma: manter na escola particular, tem o significado do status, eu posso manter meu filho na escola particular, então eu acho que passa um pouco por aí, faz o sacrifício, faz. Mas em compensação, se ele tiver que comprar uma televisão nova, ou comprar alguma coisa pra escola, a televisão nova vai ficar lá na frente ou pagar a mensalidade da escola, aquilo, a mensalidade da escola vai ficar por último, Por quê? Porque ele não tem a real dimensão da importância da escola para a vida do seu filho, tá? Então, muitas famílias passam pela questão: Ah! Meu filho está na escola particular e só.

Nessa direção, são significativas as estratégias acionadas pela instituição para atender às exigências colocadas pelas famílias. Em nossa imersão no campo, foi possível 
perceber que escolas localizadas em bairros distintos adotam práticas diferenciadas para lidar com os pais e conseguir atrair seus públicos específicos. Na escola A, por exemplo, há diversas atividades aos finais de semanas, pois as famílias pertencentes aos setores populares buscam estar na escola com mais frequência, participando das atividades culturais e pedagógicas. Na escola B, ao contrário, que atende a uma clientela pertencente às camadas médias residentes em condomínios, as famílias resistem em aderir aos convites para participar de eventos e atividades extraclasses, uma vez que buscam estilos de vida característicos dos moradores da zona oeste, fixando-se mais nos espaços de lazer dos seus próprios condomínios ou nos inúmeros shoppings da região.

\section{A construção de uma identidade}

As concepções de educação de qualidade influenciadas pelo mercado escolar acabaram por consolidar uma série de práticas (características estruturais e administrativas) adotadas pela instituição e que identificamos como formas de construção de sua identidade. Como afirma Barroso (2006), é a existência de racionalidades próprias dos atores que orientam e dão sentido (subjetivo e objetivo) às suas escolhas e às suas práticas no contexto.

Logo ao entrarmos nas duas escolas, percebemos a preocupação em criar padrões entre as escolas da rede no que se refere à sua estrutura física. Seria a busca por uma marca institucional, uma espécie de "selo de qualidade”. Do ponto de vista do espaço escolar, as escolas adotam uma arquitetura semelhante em relação ao acabamento dos prédios, à sua cor e à infraestrutura oferecida. Apesar de terem sido adquiridas em diferentes datas, as reformas realizadas nas fachadas (revestimento com pastilhas de azulejos e piso de porcelanato) obedecem a uma determinada concepção de espaço escolar.

Em toda a rede, os estabelecimentos de ensino contam com piscinas e quadras de esportes, sinalizando para a importância do espaço físico e da formação de atletas. Nos dois estabelecimentos de ensino pesquisados, considerados como referências de ensino em seus bairros, há salas amplas e equipadas, climatizadas, com quadros brancos, salas temáticas (História e Geografia) e, ainda, laboratórios de ciências e informática, funcionando e em bom estado de conservação. Ambas possuem, também, recursos multimídias, como telas interativas, mesas digitais para atividades de aprendizagem da leitura e escrita e da matemática. Como afirmam os gestores, "estamos sempre investindo em novas e modernas instalações”.

Em relação ao vestuário, os uniformes dos alunos são padronizados, assim como os dos professores e da equipe pedagógica. Os professores do primeiro segmento usam uma camiseta padronizada com o emblema da escola, enquanto os professores do segundo segmento e do ensino médio utilizam o jaleco. As coordenadoras diferenciam-se das professoras por usarem um vestido azul marinho com corte tradicional, com o nome 
da escola bordado no bolso e se distinguem, também, dos diretores, que usam terno com gravata. Pela via do vestuário, percebemos uma preocupação com a imagem da instituição, como prestadora de serviços, marcada pelo rigor e seriedade próprios das grandes empresas econômicas.

Para Ribeiro e Silva (2012), empreender esforços para entender o uso dos uniformes escolares pressupõe, então, procurar indícios da história e da memória de uma dada instituição ou de um grupo, buscando desvendar os sentidos simbólicos que esse objeto adquiriu no universo escolar e social, desnaturalizando e historicizando seus usos. Os uniformes escolares - essas coisas diminutas assim -, como nomeia Inês Dussel (2005 apud RIBEIRO e SILVA, 2012, p. 575), "marcam os sujeitos de forma muito mais profunda do que podemos imaginar”. Trouxemos essa reflexão sobre o papel do uniforme escolar, e sua simbologia, porque percebermos que o uniforme torna alguns semelhantes e outros diferentes. Ou seja, o uniforme encerra códigos, convenções e serve para hierarquizar membros de uma instituição, traduzindo as posições que ocupam no espaço escolar.

Ao analisar a cultura organizacional da escola, Nóvoa (1992) compreende que as manifestações visuais e simbólicas constituem uma categoria de análise que integra todos os elementos que têm uma forma material, passíveis, portanto, de serem identificados através da observação visual.

O caso mais evidente diz respeito à arquitectura do edifício escolar e ao modo como ele se apresenta do ponto de vista da sua imagem: equipamentos, mobílias, ocupação do espaço, cores, limpeza, conservação, etc. Um outro elemento desta categoria, particularmente importante em certas escolas, diz respeito ao vestuário dos alunos, dos professores e dos funcionários, sobretudo no que se refere ao uso obrigatório ou facultativo de uniformes e de batas. Finalmente, há a considerar todo tipo de logotipos, de lemas ou de divisas com que a escola se apresenta para o exterior, tanto em eventuais publicações, como no papel utilizado pela direcção ou nas inscrições colocadas nas paredes. (NÓVOA, 1992, p. 31)

Outra estratégia de marketing adotada são as constantes referências feitas aos exalunos que se tornaram profissionais “famosos”. Há, inclusive, na sede da escola mais antiga da rede, um museu, com a finalidade de socializar as histórias da instituição, as competições escolares, os prêmios adquiridos, o sucesso profissional de seus egressos, em uma visível preocupação de monumentalizar a sua importância na escolarização das classes $\mathrm{C}$ e $\mathrm{D}$, nas zonas oeste e norte da cidade, há muitas décadas.

Nas palavras de Nóvoa (1992. p. 31), as manifestações verbais e conceituais, "metáforas que são mobilizadas pela direção ou pelos professores para justificarem as suas ações”, constituem outra categoria de análise. 


\begin{abstract}
Nesta categoria compreendem-se, finalmente, os "heróis" e as "histórias": no primeiro caso, trata-se de indivíduos que pelas mais variadas razões entraram na história ou na lenda do estabelecimento escolar, personificando uma ideia-força organizacional ou um mito na dupla acepção do termo; no segundo caso, trata-se de histórias ou de narrativas diversas, que marcaram a vida da escola e que frequentemente se tornaram um elemento de referência social. (NÓVOA, 1992, p. 31)
\end{abstract}

No caso desta rede de ensino, chama a atenção, no museu, as fotos e a biografia escrita de indivíduos que obtiveram sucesso na vida. No nosso caso específico, um grande jogador de futebol, uma apresentadora da televisão e uma cientista mereceram grande destaque, tornando-se "heróis” por terem se escolarizado nesta instituição. Prova e propaganda da qualidade da educação desta rede, segundo a lógica dos seus gestores.

A preocupação de ser uma rede educacional de referência fica explícita no site da escola, especificamente na missão que se coloca de contribuir para o desenvolvimento de habilidades cognitivas, sociais e emocionais de seus estudantes.

Uma estratégia usada pelo grupo gestor é a de selecionar os alunos de melhor desempenho, muitas vezes atraídos por bolsas de estudos, e reuni-los em uma única escola da rede, que apresenta melhor infraestrutura física que as demais, com uma equipe de professores específica e com ensino médio propedêutico, com vistas a garantir uma boa performance discente nos exames de acesso às melhores universidades da cidade. A ideia é que, através desse grupo de "excelência” (expressão do gestor), pelo menos uma das escolas da rede se mantenha bem posicionada no ranqueamento do Enem, podendo conferir uma visibilidade de "qualidade" à instituição, em relação às famílias. Trata-se de uma das estratégias de marketing educacional adotadas na rede.

Inclusive nós temos a finalidade, como eu falei, os alunos de melhor desempenho acadêmico, nós trabalhamos esses alunos de uma forma mais intensa pra que eles possam entrar na universidade a partir do $9^{\circ}$ ano do Ensino Fundamental. Nós selecionamos os melhores alunos e colocamos nesse prédio. E tem tido um resultado muito bom (Supervisora Pedagógica).

Além disso, a partir desta visão propedêutica do ensino, tendo como foco os bons resultados nas avaliações nacionais, especificamente no Enem, tanto os diretores quanto a equipe pedagógica reconhecem a escola privada como uma alternativa à escola pública.

Na verdade, a maioria das opiniões dos gestores que parecem defender a supremacia da escola privada sobre a pública está associada às experiências pessoais negativas de trabalho que tiveram na rede pública, seja pela falta de continuidade de projetos ou da própria lógica que considera a escola publica como aquela destinada aos menos favorecidos. Bastante crítico em relação à escola pública, o proprietário reconhece que: 
Lógicas de ação de escolas privadas em rede na voz de seus gestores

Tenho muita pena dessa juventude de hoje que está dentro da escola pública porque se tornou um espaço onde passam os melhores anos da vida deles e não levam a nada. Porque a maioria das escolas, com raríssimas exceções, falta professor disso, falta professor daquilo, tem greve, não tem aula, vão à escola e o professor não vai e ninguém informa nada. (Proprietário)

Alguns entrevistados defendem o modelo de terceirização a ser adotado pelos governos, através do fornecimento de bolsas de estudos em escolas privadas como alternativa de melhoria da qualidade do ensino público. Porém, é importante deixar claro que em tais redes de ensino é quase total a ausência de regulação, pelas instâncias educacionais superiores, sobre a qualidade do ensino ministrado. O setor de inspeção escolar, ligado à Secretaria Estadual de Educação, que fiscaliza essas escolas restringese ao acompanhamento burocrático e à análise de denúncias, quando protocoladas.

Os resultados em relação ao processo de aprendizagem são analisados por indicadores subjetivos, como a percepção das famílias, a trajetória dos ex-alunos, o prestígio na comunidade. Mais recentemente, nas escolas que possuem ensino médio, o Enem tem se consolidado como o principal instrumento de diferenciação e competição entre esses estabelecimentos.

Através desse conceito de qualidade, baseado em bons resultados externos, como estratégia de marketing para atrair clientes (famílias e alunos), as escolas pesquisadas parecem adotar uma perspectiva performática e gerencialista sobre suas lógicas organizacionais. Assim, segundo Ball (2004, p. 1117) a busca por perfomatividade "encoraja as instituições a se preocuparem cada vez mais com seu estilo, sua imagem, sua semiótica, com a maneira como se apresentam as coisas mais do que como as fazem funcionar.”

\section{O trabalho pedagógico a serviço dos objetivos da escola}

Segundo os gestores, além da padronização organizacional e administrativa da rede, há a necessidade de unificação do trabalho pedagógico, a fim de permitir que a escola obtenha resultados satisfatórios nas avaliações externas ${ }^{3}$ e, com isso, preservar a imagem da instituição, na região, como um sinônimo de bom desempenho. Assim, além do investimento na estrutura física das escolas e no uso de forte linguagem midiática (site, slogan, uniforme, exploração dos dados de ranqueamento do Enem, número de aprovados nas universidades) adotada pelo departamento de marketing estratégico da instituição, a rede Ribeirão adota dois conjuntos de ações que pautam o trabalho pedagógico. De um lado, a ênfase no uso das tecnologias da comunicação e a adoção de um sistema apostilado de ensino didático.

Essas estratégias orientam a elaboração de um modelo de Planejamento Anual

3 Do ponto de vista dos resultados no ENEM, a divulgação pelo INEP\MEC revelou que as escolas da rede se posicionam desigualmente quanto ao desempenho dos alunos. Há escolas mais bem colocadas no ranking do que outras. 
unificado a ser seguido no dia a dia das salas de aulas. Cada um desses dispositivos pedagógicos é implantado diretamente, como forma de nortear o trabalho docente, e segue lógicas de ação apresentadas a seguir, juntamente com as descrições das práticas anunciadas.

Quanto à ênfase no uso das tecnologias da comunicação, a gestão investe no que chama de modernização do ensino. Afirma que é preciso superar o ensino tradicional, que marca a maioria dos professores e não garante o interesse dos alunos pela escola. Assim, a escola investe em mesas interativas educativas ${ }^{4}$, salas com computadores, lousa digital, além do uso de um portal digital ${ }^{5}$ via internet.

No entanto, os gestores afirmam que há resistência de professores ao uso desses equipamentos e, para tanto, adotam sistemas de controle do seu uso em relação a cada docente. Em uma das escolas pesquisadas, por exemplo, foram observados cartazes com a indicação dos professores que mais utilizaram o Portal Digital adotado pela instituição no corrente mês. Em outro momento, as coordenadoras pedagógicas afirmam que incentivam, individualmente, os docentes que mais se afastam do uso dessas ferramentas tecnológicas, orientando atividades e mostrando seus benefícios. Esse tipo de estratégias de encorajamento do uso dessas tecnologias parece, no entanto, também alimentar o sentimento de aprovação relativa a determinadas práticas, vistas como modelares, passando o trabalho, então, a estar subordinado a relações contraditórias de cooperação/competição entre pares (FERNANDES, 2010).

Não são identificados espaços de formação continuada com vistas a incentivar o aprimoramento profissional dos professores em relação a esse conjunto de equipamentos, não há espaços de trocas entre os pares, para as construções coletivas, a superação das dificuldades e a adequação delas às realidades de cada escola e aluno. No máximo, são apontados pelos gestores os espaços de treinamento técnico para o uso das ferramentas, permitindo a instrumentalização de seu uso por parte dos docentes e, aparentemente, reconhecendo-as como suficientes para a sua adoção como prática pedagógica inovadora.

Advogados da informática nas escolas defendem que o uso dos computadores no ensino melhora o desempenho escolar, embora nem sempre se reconheça a interveniência das condições socioeconômicas dos alunos: a diferença de qualidade do ensino resulta do uso do computador pelas escolas ou os alunos de mais elevado nível de renda e acesso à cultura são os que também estudam em escolas que têm computadores? É a primeira relação que prevalece entre as administrações educacionais

\footnotetext{
4 Trata-se de uma superfície interativa multitoque com monitores embutido em um console. Os usuários podem interagir com a superfície usando seus dedos ou uma caneta. Estas mesas interativas fornecem conteúdo educacional, recursos multimídia, jogos e muito mais.

5 Portal digital - plataforma on-line na qual os alunos têm acesso a aulas virtuais e outras ferramentas de aprendizagem, enquanto gestores e professores possuem recursos exclusivos, e os pais podem acompanhar de perto o desenvolvimento escolar de seus filhos.
} 
e fundamenta os programas de compra e distribuição de computadores. (CUNHA, 2011, p. 600).

Com isso, pode-se refletir que, para essas escolas que atendem as classes populares e a nova classe média, o uso das novas tecnologias serviria para evidenciar uma diferença em relação às escolas públicas. Pois, no momento em que essas famílias acionam a rede privada para matricularem seus filhos, buscam a ideia de ascensão social, reforçada pela lógica de Cunha (2011) de que a escola com computador é a escola destinada às camadas mais privilegiadas da sociedade e, com isso, delas se aproximam. "Prevalece uma ideia mágica sobre os efeitos dos computadores nas escolas, a ponto de escolas privadas incluí-los como itens de propaganda” (Ibid p.600).

Em relação ao sistema apostilado de ensino, a rede Ribeirão utiliza um sistema que inclui cadernos pedagógicos para professores e alunos de cada série dos segmentos da Educação Infantil, Ensino Fundamental e Ensino Médio, acesso ao portal digital, orientações pedagógicas digitais, palestras e provas unificadas. Há dez anos esse recurso vem sendo usado e comprado de uma das maiores empresas educacionais do país. Mas por que um sistema apostilado de ensino e não livros didáticos? Qual a relação do uso de um sistema apostilado de ensino e a busca por resultados nas escolas privadas?

Segundo Cunha (2011), o sistema apostilado de ensino consiste na substituição de livros didáticos por um conjunto de materiais, principalmente publicações consumíveis (apostilas) ${ }^{6}$, de modo que cada aula esteja previamente preparada para os professores, bem como as avaliações.

\begin{abstract}
Num primeiro momento, esses sistemas foram assumidos por instituições privadas de educação, compreendendo a compra de materiais pedagógicos e "pacotes" educacionais de grandes empresas, como COC, Objetivo, Positivo e Pitágoras, que incluem aluguel de marca, pelo mecanismo de franquias, avaliação e formação em serviço dos professores. As empresas vendedoras tendem a determinar não só os conteúdos a serem desenvolvidos pelos professores, mas também determinam os tempos de trabalho escolares, as rotinas e a própria metodologia do ensino. (CUNHA, 2011, p. 60)
\end{abstract}

Em levantamento histórico, Lellis (2007) constata que a maioria dos grandes sistemas de ensino atuais se originou dos cursos pré-vestibulares, um fenômeno bastante brasileiro, motivado pelo grande número de jovens da ascendente classe média das décadas de 1950 em diante, que disputava as vagas escassas das universidades. Por volta de 1980, os cursinhos começaram a se transformar em sistemas, difundindo suas apostilas por meio de escolas conveniadas, considerando que...

6 Em alguns casos, as apostilas, ao menos em seu aspecto físico, já pertencem ao passado, pois se apresentam, na forma impressa, como livros didáticos. (LELLIS, 2007) 
[...] é lógico supor que o material didático dos cursinhos, reciclados para atender alunos mais jovens, tenha atraído muita escola particular que não dispunha de pessoal docente qualificado para justificar as mensalidades cobradas. O prestígio dos cursinhos, que aparentemente "sabiam" o que era necessário para que os alunos aprendessem com vistas ao sucesso nos vestibulares, o material em si, que exibia a admirável organização necessária para resumir três anos de ensino médio e mais alguns de ensino fundamental em poucas centenas de páginas, foram fatores determinantes do sucesso inicial dos sistemas. (LELLIS, 2007, p. 03)

Ainda segundo a pesquisa de Lellis (2007), os sistemas de ensino privados, atualmente, chegam a manter convênio com uma porcentagem bastante significativa das escolas particulares de todo o país, no ensino fundamental e, no nível médio, atingem entre $40 \%$ e $60 \%$ dos estabelecimentos, além de terem o monopólio da distribuição de material didático em várias redes municipais de ensino. Os sistemas dispõem de ampla equipe de marketing, possuem gráficas, usam tecnologia avançada para promover cursos e palestras, contratam autores de textos didáticos e professores ou palestrantes que divulgam o material e instruem o professorado, além de figuras de renome para ilustrar suas peças publicitárias.

Nas escolas privadas de rede Ribeirão, a adoção dos sistemas apostilados de ensino confere a padronização desejada para o trabalho pedagógico. Como constata Cunha (2011), a empresa vendedora determina não só os conteúdos a serem desenvolvidos pelos professores, mas também determina os tempos de trabalho escolar, as rotinas e a própria metodologia do ensino.

Além disso, a adoção dos sistemas apostilados de ensino funciona como importante estratégia de marketing, pois a propaganda apresenta esses sistemas como responsáveis pelo bom resultado de uma série de escolas privadas, principalmente nos ranqueamentos nacionais do Enem. No caso da rede Ribeirão, é um sistema mineiro o responsável por garantir uma "Nova Didática” (CUNHA, 2011, p.602) para as práticas pedagógicas das escolas e que ainda oferece, como parte do "pacote", a chamada orientação pedagógica, com ciclos de palestras, visando treinar o professorado para o uso do material.

Na rede Ribeirão, esse sistema é utilizado por cada escola para a realização do planejamento geral, que consiste em um cronograma semanal de trabalho, destacandose as atividades pedagógicas que devem ser desenvolvidas, os exercícios, os materiais e os projetos adotados para cada ano.

Nomeado Planejamento Anual e apresentado como guia para todos os professores e alunos das quinze escolas, é elaborado pela diretoria de ensino da rede e por um grupo selecionado de professores. Para completar, a avaliação bimestral é elaborada a partir do Planejamento, o que traz bastante tensão entre alunos e professores, pois a verificação do rendimento tem como pressuposto o fato de o planejamento ter sido integralmente cumprido. 
O próprio proprietário evidencia essa preocupação de gerenciar a rede a partir de padrões de funcionamento e de uma política de resultados:

Tem todo um planejamento no sentido de apurar (o andamento da rede) inclusive a qualidade do trabalho. A cada bimestre eu recebo um relatório onde fica quantificado turma por turma o desempenho. Então se houver uma discrepância nesta ou naquela turma a gente chama o diretor para entender o porquê. (Proprietário)

Quanto às justificativas apresentadas pela equipe de gestores para a escolha desse sistema, além da necessidade de unificar o trabalho da rede, destacam-se a "nova didática” proposta pelo material e a superação da baixa formação dos professores recrutados por esse tipo de escola de rede,

Com isso, a equipe pedagógica deixa claro que acredita na proposta didática e metodológica do sistema apostilado, mesmo resaltando o papel regulador que ele tem sobre o trabalho docente. Para a equipe, a lógica didática do sistema apostilado faz com que o professor interaja com o manual e "leve o aluno a pensar". O caráter processual marcado por uma sequência organizacional rígida, que precisa ser seguida pelo docente, é visto pela equipe pedagógica como um facilitador da aprendizagem.

[...] na realidade aqui vem tudo... todo o livro indica até onde o professor vai para um primeiro teste, até onde ele vai em um segundo momento da avaliação. Ele vai dar uma atividade que não é um teste nem uma avaliação em sala, o norte está todo aqui. Dividido por semanas [...].(Coordenadora pedagógica)

Para os diretores e coordenadores entrevistados, esse tipo de sistema de ensino exige, do professor, o cumprimento do planejamento semanal das aulas e a necessidade de estudo. De um modo ou de outro, o que os gestores assinalaram foi que a resistência dos professores ao sistema apostilado de ensino passou a obrigá-los a estudar, realizar plano de aula, levar os alunos à reflexão.

Como uma hipótese para a resistência e a dificuldade em operar com o sistema apostilado foi aventada a má qualidade da formação do professor nos cursos de pedagogia e licenciatura, no que se refere ao grupo de discentes que acessam essa rede. Para os gestores, a formação é essencialmente teórica, em detrimento da prática, impedindo o desenvolvimento de competências e habilidades necessárias a esse novo aluno do século XXI. É forte a crítica à formação pedagógica dos professores disponíveis no mercado, pois reconhecem que as faculdades de educação não vêm formando bem esses profissionais. Alguns chegaram a declarar a falta que o curso normal faz na formação dos novos docentes para a prática.

Hoje no mercado você não acha no meio do ano pessoas, digamos assim, com conhecimento, profissionais de qualidade, você não encontra. 
Professor é difícil! (Diretor da escola B).

Assim, o uso do sistema apostilado associado a outras ações normativas da própria escola, como o acompanhamento dos planos de aulas, a prova única, o acesso ao portal, o cumprimento de um cronograma e o controle dos resultados, justifica a busca da qualidade de ensino, dada a fragilidade da formação dos professores de hoje, independentemente da instituição de ensino superior, seja pública ou privada. Para o conjunto dos entrevistados, a formação inicial não está, atualmente, capacitando os professores para o mundo da sala de aula, seja do ponto de vista do domínio de conhecimentos e competências, seja do ponto de vista dos procedimentos didáticos e gestão da classe. As fortes críticas feitas à universidade e instituições isoladas, a despeito de sua posição no mercado do ensino superior, levam os gestores a admitirem a dificuldade de encontrarem, hoje, bons professores, já que os concursos para as redes municipais e estaduais absorvem, anualmente, uma parcela do professorado recém-formado.

\section{Problematizando a realidade: descompassos encontrados e a regulação do trabalho docente}

Em que pesem as representações dos gestores sobre o ensino, quais os desencontros entre os objetivos anunciados pela proposta pedagógica da escola e as lógicas empresariais e performáticas identificadas? Quais elementos se mostram contraditórios ou comprobatórios, favorecendo uma reflexão sobre essa realidade e, principalmente, sobre o trabalho dos professores?

Fica evidenciado que as percepções dos gestores exaltam a qualidade do material pedagógico e a importância das tecnologias da comunicação para a formação do aluno, além da necessidade de complementar a formação dos professores através da definição de um direcionamento pedagógico instrumental. Em contrapartida, a literatura no campo da Educação tem sido muito crítica a respeito da natureza e do conteúdo dos sistemas apostilados de ensino, como também, sobre a regulação do trabalho docente.

Uma crítica feita por professores de ensino médio de três municípios paulistas que utilizam o sistema apostilado de ensino, pesquisados entre 2006 e 2008, foi dirigida ao fato de não terem voz, de não serem sujeitos da elaboração das propostas que são implantadas nas escolas e de serem culpabilizados quando as medidas que chegam não saem a contento (FERNANDES, 2010, p. 82). A sobrecarga de tarefas imposta pelo sistema apostilado e a ausência de tempo para ler, para preparar o material para as aulas, para buscar novas informações e para se apropriarem de novos conhecimentos foram apresentados por esses professores como uma limitação para a realização dos projetos (FERNANDES, 2010).

Preocupa, também, a seleção dos conteúdos por essas instâncias empresariais da educação, sem a participação dos professores. Quais as vertentes ideológicas priorizadas 
por essas instituições? Cunha (2011) identifica que, por traz da seleção de conteúdos curriculares e disciplinares, há a pressão ideológica dos mercados sobre os currículos escolares. Assim, quando se constata um discurso de padronização/homogeneização de conteúdos e currículos escolares com vistas a instaurar uniformidade nos processos pedagógicos, é preciso estar atento às vertentes ideológicas hegemônicas.

Uma terceira crítica que aparece é relativa à perda de poder dos professores que, para Correa e Matos (2001), se assentava, anteriormente, em uma delegação cognitiva muito evidente: os professores eram depositários do saber científico. Para esses autores, a perda dessa especificidade do trabalho do professor do ensino médio tirou o chão dos professores. E, mais, “atividades tradicionalmente desenvolvidas pelas equipes pedagógicas das escolas como formação continuada dos professores, efetivo acompanhamento das atividades docentes, investimento na produção e distribuição de materiais didáticos aos alunos, processos de avaliação interna e externa.” (ADRIÃO, GARCIA, BORGUI e ARELARO, 2009) são transferidas para as empresas educacionais, tornando-as, de fato, gestoras das diversas redes de ensino e idealizadoras dos conceitos de qualidade e dos próprios objetivos da educação.

Ressalta-se que, mesmo que a maioria dos estudos citados se dê pela análise dos sistemas apostilados nas redes públicas, essas conclusões ajustam-se, perfeitamente, à realidade das escolas pesquisadas da rede privada Ribeirão, no atendimento aos setores mais populares. Principalmente porque as lógicas de ação adotadas pelos gestores, para ambas as redes, públicas e privada, justificam-se, aparentemente, pelos mesmos ideais de controle do trabalho docente e do currículo unificado com vistas a garantir bons resultados em avaliações externas (Prova Brasil ou Enem), favorecendo a competição entre as escolas.

O que não se pode negar é que, na perspectiva de uma política de resultados, há uma forte regulação sobre o trabalho dos professores. O sistema apostilado de ensino contribui para o comprometimento da autonomia docente e pode comprometer o processo de profissionalização dessa categoria profissional.

Segundo Fernandes (2010), dentro dessa lógica empresarial, muitas vezes, o ensino passa a seguir regras que permitem atingir metas determinadas de maneira exógena, alterando profundamente o trabalho dos professores.

Cunha (2011) vai mais além e ressalta que é preciso estar atento para perceber as interferências dos mercados, em suas vertentes ideológica e econômica, nos currículos escolares, sejam públicos ou privados. $\mathrm{O}$ autor destaca que a débil autonomia do campo educacional propicia as interferências de diversos agentes, cada qual em busca de vantagens ideológicas, econômicas, frequentemente ambas. Essas interferências, por sua vez, dificultam o avanço do processo de autonomização do campo, acionando, em consequência, um movimento de ação recíproca viciosa, que não propiciará, certamente, a ampliação nem a melhoria da educação brasileira. 
O setor privado, na visão de Cunha (2011), particularmente o destinado à formação das elites, sempre soube cuidar de sua autonomia, atuando para dispor de bancada parlamentar e representação nos órgãos de deliberação coletiva dos sistemas educacionais. Mas e o setor privado educacional que se institui recentemente, destinado às novas classes médias, como se estruturam? A pesquisa mostra que, em semelhança à educação pública, as escolas privadas da rede pesquisada mostram-se tão ou mais vulneráveis a tais interferências mercadológicas destacadas nesse estudo.

Neste artigo não se trata de um debate da relação público-privado em relação aos sistemas de ensino, mas do setor privado com privado, marcado pela hegemonia de grandes empresas educacionais que controlam o campo mercadológico do ensino. A esfera privada das escolas em rede que dispõe de poucos recursos financeiros e a necessidade de se manter no mercado altamente competitivo favorecem a apropriação de lógicas gerenciais e performáticas, gerando crise entre conceitos de qualidade de ensino e os próprios objetivos da educação. O modelo propedêutico destinado às elites parece que se consolida nas escolas privadas destinadas às classes populares, gerando precarização e instrumentalização do trabalho docente e, infelizmente, poucos espaços de reflexão ou mudança.

\section{Considerações Finais}

A partir dos resultados obtidos nas entrevistas com os oito gestores, foi possível perceber que uma série de lógicas norteia o funcionamento dessa rede de ensino. Na rede Ribeirão, a figura do diretor proprietário é determinante e estruturante para a caracterização, a história e as diretrizes futuras da rede. Há, ainda, um aparente consenso entre os membros da equipe gestora em relação à filosofia da instituição, funcionando sob a forma de lógicas de ação (BARROSO, 2006). Esse conceito é frequentemente usado nos estudos sobre as organizações e é definido como resultado da descrição e interpretação do modo como uma instituição se organiza e coordena sua ação coletiva. Para o autor, a concepção de lógica de ação remete à existência de racionalidades próprias dos atores que orientam e dão sentido (subjetivo e objetivo) às suas escolhas e às suas práticas no contexto de uma ação individual ou coletiva.

As lógicas de ação que pautam o funcionamento dessa rede, assinaladas pelos entrevistados, permitem compreender o contexto em que se dá a adoção de sistemas apostilados de ensino em duas escolas privadas de rede, situadas na cidade do Rio de Janeiro. Não se trata de uma escolha arbitrária ou individual por esse ou aquele modelo de escola. O que se evidencia é o predomínio de uma lógica gerencialista, baseada na busca por uma determinada concepção de qualidade, baseada nos resultados, na centralização de ações, na valorização do empreendedorismo pessoal, na responsabilização dos membros (DOURADO, 2007).

Essa lógica vem atender a um público escolar constituído por extratos das classes 
populares e de classes médias emergentes, portadoras de expectativas específicas sobre a função social da escola e sobre o conceito de qualidade de ensino, afastando-se da percepção da escola como instituição social, transmissora de valores, orientada por fins político-pedagógicos que extrapolam a relação custo-benefício (DOURADO, 2007). Para esse autor, essa concepção baseia-se na autonomia da instituição para construir seu projeto pedagógico de acordo com suas especificidades.

Mais do que tudo, estas análises preliminares podem nos conduzir para um debate mais amplo, fundamentado no tema da heterogeneidade do mercado escolar, em que coexistem diferentes modelos de escolas, direcionados a diferentes segmentos das camadas sociais. Mais do que defender o monopólio do Estado pela educação, a existência, hoje, de um mercado escolar altamente competitivo remete às desigualdades educacionais e sociais e exige de nós a luta para que a escola pública se torne uma instituição que garanta a eficácia e a equidade, em termos de qualidade de ensino e de justiça no que diz respeito às diferenças de toda ordem.

\section{Referências}

ADRIÃO, T.; GARCIA, T.; BORGHI, R.; ARELARO, L. Estratégias municipais para a oferta da educação básica: análise das parcerias público-privado no Estado de São Paulo. Projeto de pesquisa. 2009.

ALMEIDA, Maria Isabel A reconstrução da profissionalidade docente no contexto das reformas educacionais - vozes dos professores na escola ciclada. In: SILVA, A. M. M. et al (org). Políticas educacionais, tecnologias e formação: repercussões sobre a didática e as práticas de ensino. Recife: Endipe, 2006.

BALL, Stephen, Perfomatividade, privatização e Pós Estado de Bem-Estar. Campinas, Educação e Sociedade, vol.25, n.89, dez 2004. Disponível em: http://www.scielo.br/ scielo.php?pid=S0101-73302004000400002\&script=sci_abstract\&tlng=pt. Acesso em março de 2018.

BARROSO, João. A regulação das políticas públicas de educação: espaços, dinâmicas e actores. Lisboa: Educa Autores, 2006.

CORREA, J.A; MATOS, M. Solidões e solidariedades nos cotidianos dos professores. Porto: ASA, 2001.

CUNHA, Luiz Antônio. Contribuição para a análise das interferências mercadológicas nos currículos escolares. Revista Brasileira de Educação, Rio de Janeiro, v. 16 n. 4, set.-dez., 2011. Disponível em: http://www.scielo.br/pdf/rbedu/v16n48/v16n48a04. 
pdf. Acesso em março de 2018.

DOURADO, Luiz Fernandes. Políticas e gestão da educação básica no Brasil: limites e perspectivas. Educação \& Sociedade, Campinas, v.28, n.100, out. 2007. Disponível em: http://www.scielo.br/pdf/es/v28n100/a1428100.pdf. Acesso em março de 2018.

DUSSEL, Inês. Cuando las apariencias no engañan: uma historia comparada de los uniformes escolares em Argentina y Estados Unidos (siglos XIX-XX). Pro-Posições, Campinas, v. 16, n. I (46), p. 65-86, jan./abr. 2005.

FERNANDES, Maria José da Silva. As recentes reformas educacionais paulistas na visão dos professores. Belo Horizonte, Educação em Revista, v.26, n.3, dez. 2010. Disponível em: http://www.scielo.br/scielo.php?pid=S0102-46982010000300005\&script=sci_ abstract. Acesso em março de 2018.

JORNAL O GLOBO (24/04/2013). Kroton e Anhanguera Educacional fazem acordo de associação. Disponível em: http://g1.globo.com/economia/negocios/noticia/2013/04/ rede-de-ensino-kroton-vai-incorporar-anhanguera-em-acordo-com-acoes.html. Acesso em abril de 2013.

LELLIS, Marcelo. Sistemas de ensino versus livros didáticos: várias faces de um enfrentamento. São Paulo: Abrale. 2007. Disponível em < http://www.abrale.com.br/ wp-content/uploads/sistemas-ensino-livros-didaticos.pdf>. Acesso em: 10 set. 2018

NÓVOA, Antonio. Para análise das instituições escolares. In NÓVOA, Antônio (org). As organizações escolares em análise. Lisboa: Publicações Dom Quixote, 1992

OLIVEIRA, Romualdo. A transformação da educação em mercadoria no Brasil. Campinas, Educação e Sociedade, Vol. 30, n.108, out 2009. Disponível em: http:// www.scielo.br/pdf/es/v30n108/a0630108.pdf. Acesso em março de 2018.

RIBEIRO, Ivanir; SILVA, Vera Lucia Gaspar. Das materialidades da escola: o uniforme escolar. Campinas, Educação e Sociedade, Vol.38. n.3, set. 2012. Disponível em: http://www.scielo.br/pdf/ep/v38n3/03.pdf Acesso em março de 2018.

SAMPAIO, Maria das Mercês Ferreira; MARIN, Alda Junqueira. Precarização do trabalho docente e seus efeitos sobre as práticas curriculares. Campinas, Educação e Sociedade, Vol.25, n.87, dez 2004. Disponível em: http:// stoa.usp.br/gepespp/files/3116/17472/Precariza\%C3\%A7\%C3\%A3 o+do+trabalho+docente+e+seus+efeitos+sobre+as+pr\%C3\%A1ticas+curriculares. pdf Acesso em março de 2018.

SILVA, Maria Vieira; SOUZA, Silvana Aparecida. Educação e responsabilidade 
empresarial: "novas” modalidades de atuação da esfera privada na oferta educacional. Campinas, Educação e Sociedade., Vol. 30, N. 108, P. 779-798, Out. 2009. Disponível em: http://www.scielo.br/ scielo.php?pid=S0101-73302004000400002\&script=sci_ abstract\&tlng=pt. Acesso em março de 2018.

SOUZA, Jessé. Ralés, batalhadores e uma nova classe média. Entrevista_UNISINOS, São Paulo, 2011. Disponível em http://www.ihu.unisinos.br/entrevistas/40345-ralesbatalhadores-e-uma-nova-classe-media-entrevista-especial-com-jesse-de-souza. Acesso em: 21 abr. 2014.

Recebido em: 08/03/2018

Aprovado em: 03/04/2019 